\title{
Formation of an effective management structure for enterprises in the energy sector of the economy
}

\author{
Zhanna Lemesheva ${ }^{1,{ }^{*}}$, Oksana Yurchenko $^{1}$, Myron Karpovich $^{2}$, Zinaida Petrikova ${ }^{2}$, Natalya \\ Bratishko $^{3}$ and Larisa Garipova ${ }^{3}$ \\ 'Peoples' Friendship University of Russia (RUDN University), Miklukho-Maklaya Street, 6, \\ Moscow, 117198, Russia \\ (The publication was prepared with the support of the "RUDN University Program 5-100") \\ ${ }^{2}$ Voronezh State Technical University, Moscovskiy prospect, 14, Voronezh, 394026, Russia Moscow \\ ${ }^{3}$ State University of Technologies and Management named after K.G.Razumovsky (Bashkir branch), \\ Smolenskaya Street, 34, Meleuz, 453850, Russia
}

\begin{abstract}
The aim of the study is to form an effective management structure for enterprises in the energy sector of the economy, operating in an unstable external environment. The result of the analysis of modern types of organizational structures is the proposed form of management structure, which takes into account the construction specifics. The developed set of guidelines for assessing the efficiency of the management structure can be applied not only in the construction industry but also in other industries, including in the energy sector. Special attention is paid to the analysis of external and internal factors affecting the activities of enterprises. Various structures of enterprise management are modeled using mathematical models and the preference matrix method when assessing the integral indicator of the management structure efficiency.
\end{abstract}

\section{Introduction}

The problems associated with the formation of effective methods of building flexible and adaptive management structures are always associated with an assessment of their efficiency, which is also among the most pressing problems, both in their economic practice and in scientific papers [1-4].

The influence of external and internal factors on the efficiency of operation of enterprises in the energy sector of the economy forces them to form more and more complex management systems in accordance with the requirements of the time and depending on the direction of the changes. This is due to the fact that, over time, the structures and mechanisms of management that had previously effectively performed their functions begin to put brakes on their development without timely evolutionary and innovative transformations of the internal environment of a building organization that are relevant to changes in the external environment.

\footnotetext{
*Corresponding author: lemesheva.87@bk.ru
} 


\section{Materials and methods}

The formation of an effective management structure is a complex problem, which can be solved only through a deep socio-economic analysis of the external environment and organizational and technical analysis of its internal environment (Fig. 1).

Taking into account the study of the current state of the construction market, analysis of the problems and the influence of various factors on the economic activities of the organizations of the relevant segment, predictive assessments of their activities in the near future were formulated.

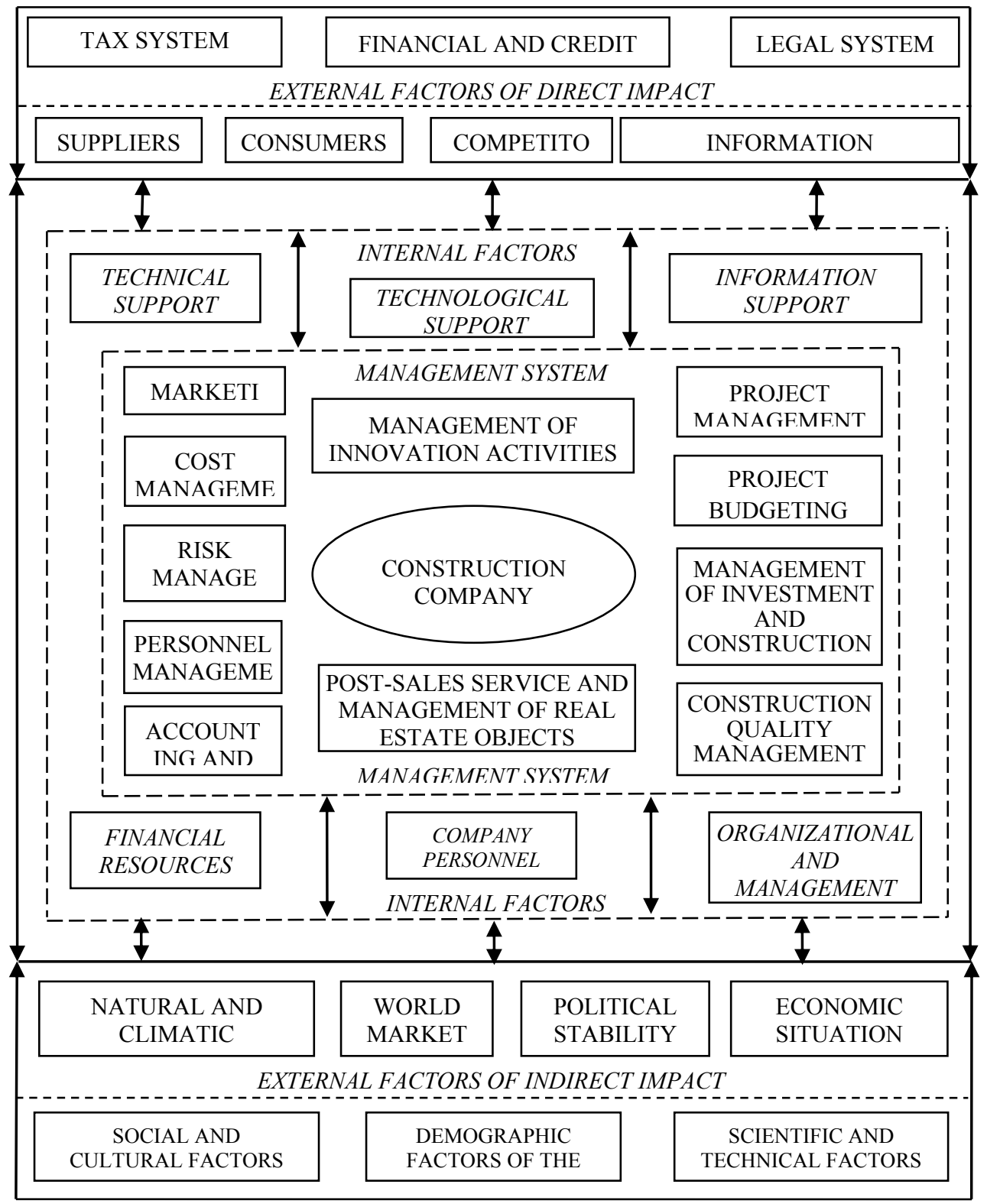

Fig. 1. The impact of external and internal factors on enterprises of energy companies. 
On the one hand, a modern construction organization that manages development projects in the low-rise housing segment is an integrated construction structure that unites a certain number of specialized companies, each of which takes its place in a certain hierarchy, has its own purpose and functions within a single management loop [5]. On the other hand, the construction organization-developer is the management core, which, using the mechanism of outsourcing of certain functions and processes to these companies, takes responsibility for the final result of the successful completion of the project (Figure 2).

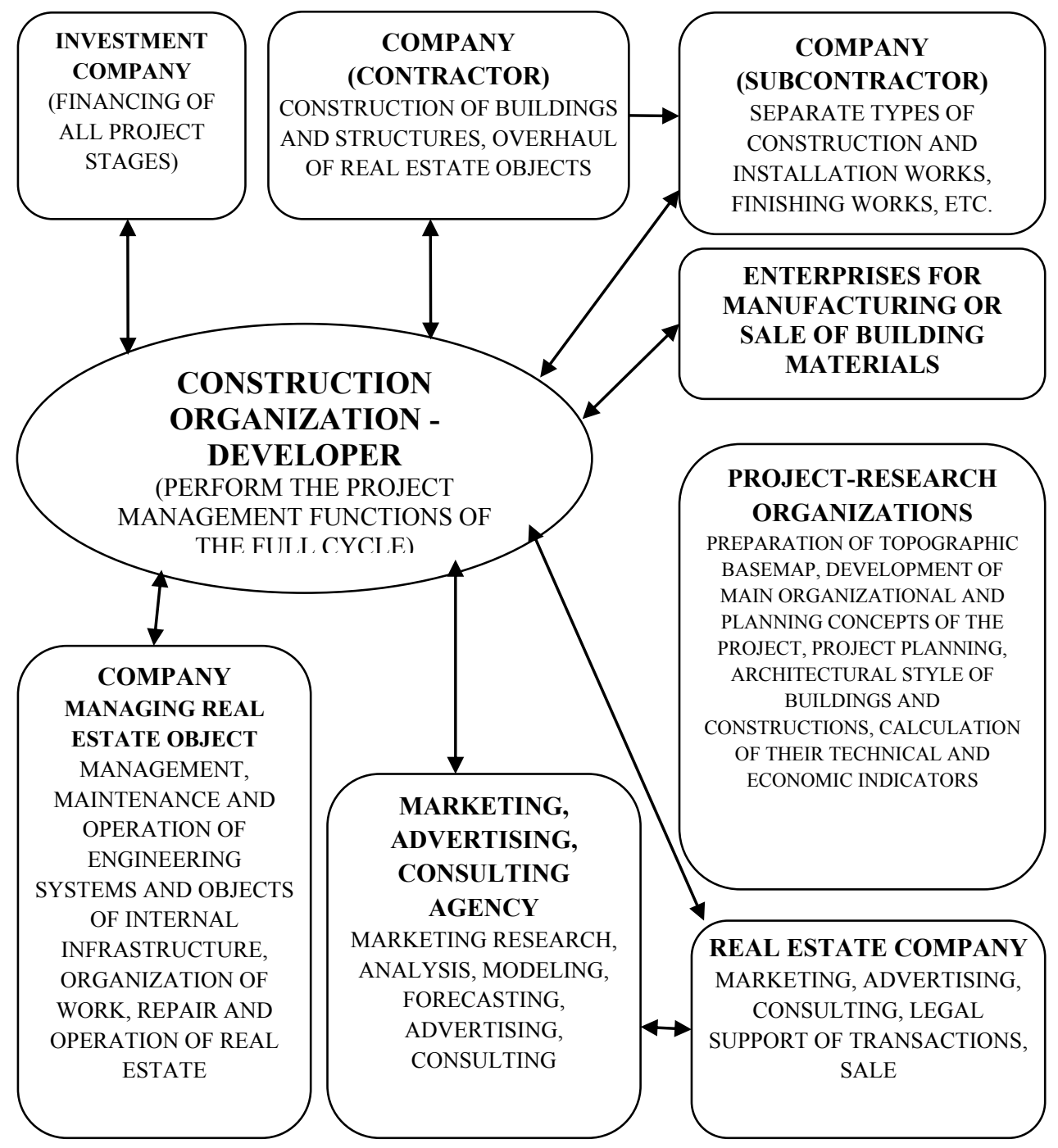

Fig. 2. The structure of the construction organization in the implementation of development projects in the sector of low-rise construction.

As the Russian experience in the development of construction organizations operating in the sector of low-rise construction shows, integrated construction structures uniting all the necessary resources for implementing a development project - from investing companies to companies managing existing real estate objects and realizing them to the final consumer, are more efficient and adapted to existing economic conditions. 


\section{Results}

The efficiency of the management structure of an investment and construction organization is characterized by its speed as a single integrated system and its end results, i.e. the organization's ability to achieve its goals through the orderly interaction of its subsystems and structural elements in the most economical way.

Assessment of the efficiency of the management structure of a construction organization is a comprehensive and systematic analysis of its economic activity indicators, in which two complementary approaches should be distinguished: qualitative and quantitative.

The quantitative approach is based on the assessment of generalized indicators reflecting the activities and results of the construction organization over a certain period of time, such as, for example, construction volume, sales volume and profitability, payback period and return on investment, management costs, etc.

The qualitative approach is focused on assessing the efficiency of the management structure in terms of its maximum compliance with the goals set by the construction organization and reflects the efficiency of the management system and mechanism, the efficiency of the goal setting system, the efficiency of the communication structure and functional elements, and also the personnel qualifications, the efficiency of the marketing system, the quality of construction, etc.

Taking into account these aspects, the study proposes a method for assessing the efficiency of the management activities of a construction organization in relation to the degree of achievement of its goals [6,7].

The method includes two assessment options and consists of the following stages:

Stage 1. It is necessary to select key performance indicators of the company, approved for a specific period (for example, next year) and most reflecting the achievement of goals set by management for the implementation of a given strategy.

Stage 2. The maximum for each planned target value for the year will be 10 points, since the optimal operating efficiency of the management will be 100 points $(10 \times 10)$, equivalent to $100 \%$.

Step 3. The calculation and assignment of weight points is carried out taking into account their value to achieve the goals of a given strategy. According to the results of the planning period, the actual values are converted into points by a simple proportion (assignment of weighting factors to them). The total significance of the weighting factors is also equal to 10 points.

In case of overspending and exceeding the optimal level of efficiency, it is necessary to subtract the resulting point excess from the optimal efficiency value, since the actual efficiency can be equal to either $100 \%$ (the indicator has reached the optimal value) or it should be less than the optimal value.

The second variant of the assessment method is different in that the assessment of indicators must be made in the range from their minimum value in the past period to the planned level of the assessed period.

When a planned and actual change has the same sign, the score is assigned to the actual value on the basis of the usual proportion. If growth was planned in comparison with the previous year, and in fact the indicator did not reach the planned level, then the score is calculated differently.

In the case when the indicator has decreased, the point corresponding to a decrease should be added to -10. Its calculation is carried out as a quotient of dividing the actually obtained change of the indicator to the sum corresponding to 1 point in the calculation on the level of the optimal change. The efficiency of the work to achieve the goals is also determined by adding the products of the points of the actual values of the indicators to the 
points of their significance for achieving the goals of a given strategy. The optimal efficiency, as in the first variant of the method, will be $100 \%$.

It should be noted that of all the variety of indicators found in the scientific economic literature, reflecting the efficiency of economic activities of a construction organization, very few would characterize its organizational and structural aspect [8].

In this regard, the paper proposed four groups of indicators characterizing various aspects of organizational and management processes and functions that are not used in the usual practice of analyzing the economic activities of construction organizations.

The efficiency of the management structure is presented in the study as a function

$$
\mathrm{E} .=f\left(\mathrm{~K}_{\mathrm{t} .}, \mathrm{K}_{\mathrm{m}}, \mathrm{K}_{\mathrm{s} .}, \mathrm{K}_{\mathrm{f} .}\right) \text {, }
$$

where $K_{\mathrm{t}}$ - indicator of the efficiency of the target setting mechanism; $K_{m}$ - generalized indicator of the efficiency of the management system; $K_{s}$ - generalized indicator of the structural and functional efficiency of the organization of management; $K_{f}$ - generalized indicator of the efficiency of the structure of relations.

When determining the values of these groups of indicators by an expert method, it was taken into account that expert assessment is subjective, and expert judgments are usually expressed in a qualitative, rather than in a quantitative form. Considering this aspect, the Harrington scale was used as the basis for determining the intervals and calculating the numerical values of the above mentioned indicators, which is of a universal nature and is widely used in expert assessments.

The proposed modification of the Harrington scale in assessing the indicators characterizing the efficiency of the management structure is as follows (Table 1).

Table 1. Scale of values of indicators for assessing the efficiency of the management structure.

\begin{tabular}{|c|c|c|c|c|c|}
\hline \multicolumn{2}{|c|}{ Score in points } & \multirow{2}{*}{$\begin{array}{l}\text { Informative description of } \\
\text { the resulting values }\end{array}$} & \multirow[t]{2}{*}{ interval } & \multirow{2}{*}{$\begin{array}{l}\text { Calculation of } \\
\text { numerical value }\end{array}$} & \multirow{2}{*}{$\begin{array}{l}\text { numerical } \\
\text { value }\end{array}$} \\
\hline $\begin{array}{l}\text { Degree of } \\
\text { significance }\end{array}$ & point & & & & \\
\hline very high & 5 & high level & $1.0-0.8$ & $(1.0-0.8) / 2$ & 0.9 \\
\hline high & 4 & level above average & $0.8-0.63$ & $(0.8-0.63) / 2$ & 0.715 \\
\hline average & 3 & average level & $0.63-0.37$ & $(0.63-0.37) / 2$ & 0.5 \\
\hline low & 2 & level below average & $0.37-0.2$ & $(0.37-0.2) / 2$ & 0.285 \\
\hline very low & 1 & low level & $0.2-0.0$ & $(0.2-0.0) / 2$ & 0.1 \\
\hline
\end{tabular}

Due to the fact that the integral efficiency of the management structure in the study is determined by the arithmetic mean value of the estimated groups of indicators, and the efficiency of target setting is the ratio of the results of the organization's activities to achieving the goals set for this period, the indicator of the efficiency of the target setting mechanism has the following form:

$$
\left.K_{t}=\left((P / T) / G_{i}\right)\right) A_{i} q_{i}
$$

where for indicator $P$ we take the value obtained in the assessment of the efficiency of the company's management activities; for the indicator $T$ - a value that reflects the level of achievement by the company of the specified goals for the same period of time; $G i$ - the number of groups of indicators used in assessing the integral efficiency of the management structure; $A i$ - score of the indicator of the efficiency of the target setting subsystem in the management structure; $q_{i}$ - the weight factor of the $i$-th subsystem. 


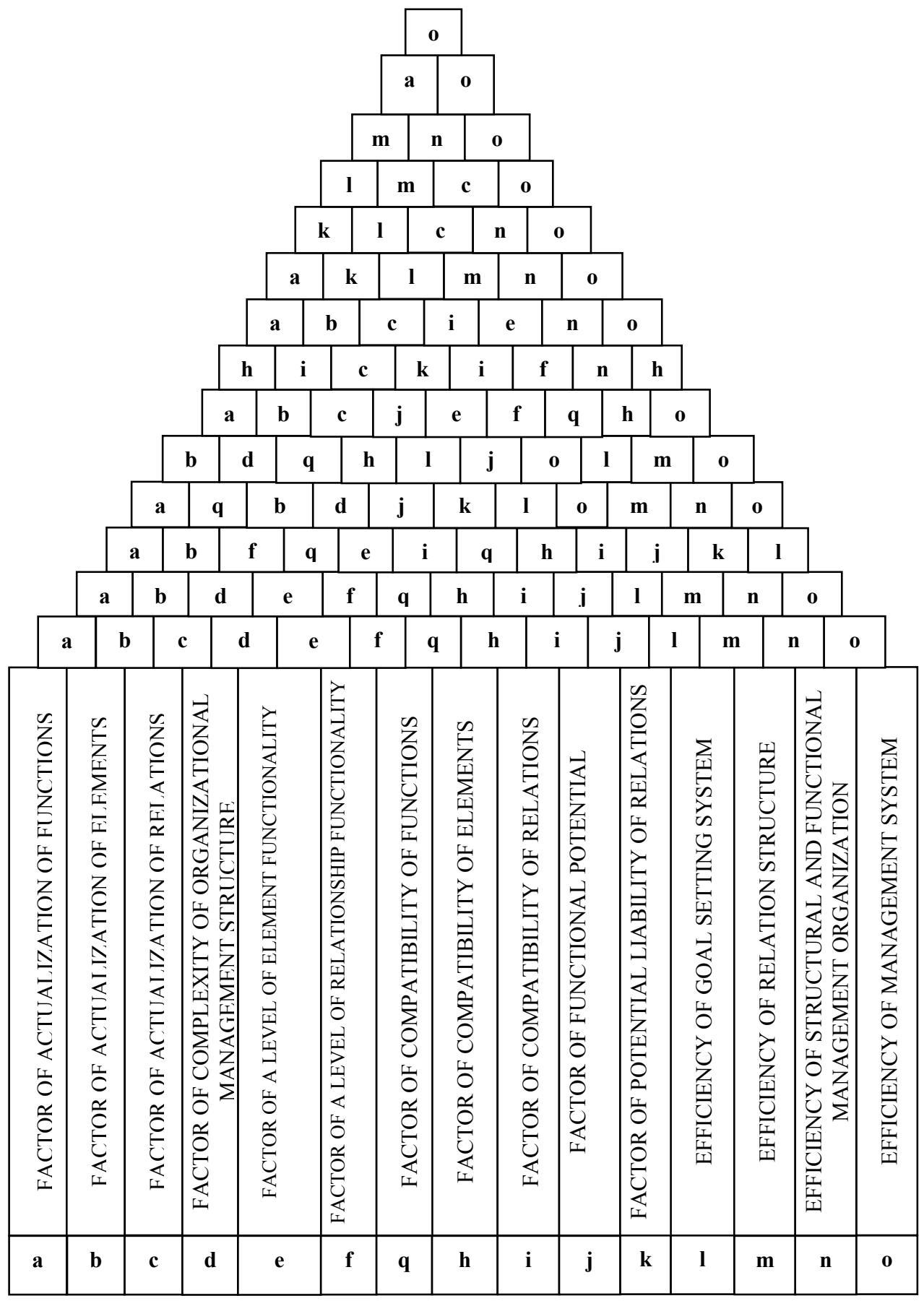

Fig. 3. The preference matrix method for assessing the integral indicator of the efficiency of the management structure.

Thus, using the methodological approaches proposed in the paper, it is possible to determine the integral efficiency of the management structure of the assessed development 
company, and the resulting quality indicator (according to the Harrington scale) has a rather high numerical value.

The main disadvantage of the presented methodological approach is the direct distribution of weight points, which pushes for some manipulations consisting in the fact that especially high weights are received by goals that meet either the desired alternative or the personal preference of the expert (specialist). In this case, the preference matrix method looks more attractive. In the process of its use, a much deeper comparison of individual weights is carried out, which provides a more adequate assignment of points and weights to the indicators.

In the preference matrix (Figure 3), the assessed criterial properties of functions, relations, elements, their values or weights are assigned letters, which are then compared in pairs with each other. At the point of intersection of two corresponding lines, a letter is marked every time, which, when directly compared, is given more weight. Further, weighting of individual criteria is obtained on the basis of the absolute number of their occurrences in the matrix.

\section{Conclusion}

As a result of the study, the main provisions were formulated, reflecting the authors' contribution to the development of theoretical and practical aspects and methodological provisions related to the formation of a more sophisticated management structure of a construction organization. The developed methodology for assessing the efficiency of the enterprise management structure may be applied not only in the construction industry but also in other branches of material production. The universality of the methodology is due to the identification of promising areas and the development of effective forms and methods of managing production enterprises.

\section{References}

1. R.F. Rolima, E. Santos, L. Meirac, Region. XI Congreso de Ingenieria del Transporte, 160-169 (2014)

2. S. Naresh, K. Malhotra, Journal of Business Research 69, 5671-5681 (2016)

3. I.M. Horta, A.S. Camanho, Expert Systems with Applications 41, 974-983 (2014)

4. J. Deng, L. Wang, Swarm and Evolutionary Computation 32, 121 -131 (2017)

5. P. Neirotti, E. Raguseo, Information \& Management 54, 139-153 (2017)

6. R. Golov, T. Narezhnaya, N. Voytolovskiy, V. Mylnik, E. Zubeeva, MATEC Web of Conferences 193 (2018) https://doi.org/10.1051/matecconf/201819305080

7. I. Lukmanova, R. Golov, E3S Web of Conferences 33 (2018) https://doi.org/10.1051/e3sconf/20183302047

8. B. Marchi, S. Zanoni, M. Pasetti, 21st Summer School F. Turco of Industrial Systems Engineering (Naples, 2016)

9. O. M. Smirnova, International Journal of Civil Engineering and Technology, No.9, V.8, 1724-1732 (2018)

10. O. M. Smirnova, International Journal of Civil Engineering and Technology, No.9, V.8, 1733-1740 (2018)

11. A.R. Bril, O.V. Kalinina, I.V. Ilin, Economic Analysis of Projects in the Improvement of the HR Management System of Enterprises, Proc. of the 29th IBIMA Conference. Pp. 2268-2277 (2017) 